\title{
Differential impact of intimal tear location on aortic dilation and reintervention in acute type $I$ aortic dissection after total arch replacement
}

\author{
Woon Heo, MD, ${ }^{\text {a,b }}$ Suk-Won Song, MD, PhD, ${ }^{c}$ Tae-Hoon Kim, MD,${ }^{c}$ Jin-Seong Lee, RN, \\ Kyung-Jong Yoo, MD, PhD, ${ }^{\mathrm{d}}$ Bum-Koo Cho, $\mathrm{MD}, \mathrm{PhD},{ }^{\mathrm{e}}$ and Hye Sun Lee, $\mathrm{PhD}^{\mathrm{f}}$
}

\section{ABSTRACT}

Objective: The study objective was to evaluate the differential impact of intimal tear location on aortic dilation and reintervention after total arch replacement for acute type I aortic dissection.

Methods: From 2009 to 2016, 85 patients underwent total arch replacement for acute type I aortic dissection with residual dissected thoracoabdominal aorta. Forty patients $(47 \%)$ underwent serial computed tomography scans that were sufficient for analysis. Among these, $14(35 \%)$ underwent total arch replacement via the frozen elephant trunk procedure. Intimal tears were analyzed (size and number) at 3 different levels (level 1, proximal descending thoracic aorta; level 2, distal descending thoracic aorta; level 3, abdominal aorta). Aortic diameter was measured at 4 levels (pulmonary artery bifurcation, celiac axis, maximal abdominal aorta, and maximal thoracoabdominal aorta) using serial follow-up computed tomography scans. The linear mixed model for a repeated-measures random intercept and slope model was used. The rate of freedom from reintervention was analyzed.

Results: In the unadjusted analysis, initial diameter of pulmonary artery bifurcation level, number of intimal tears, presence of 3- or 5-mm intimal tears, and frozen elephant trunk were not significant factors for aortic dilation or shrinking. The significant factors for aortic dilation were intimal tear location and number of visceral branches from the false lumen. The 3-year freedom from reintervention rate was significantly higher in patients with intimal tears $3 \mathrm{~mm}$ or greater at level 3 than in those with tears at level $1(94.1 \%$ vs $37.5 \%$, log-rank, $P<.001)$.

Conclusions: Intimal tear in the proximal descending thoracic aorta is the most important factor for aortic dilation and reintervention in acute type I aortic dissection after total arch replacement. (J Thorac Cardiovasc Surg 2019;158:327-38)

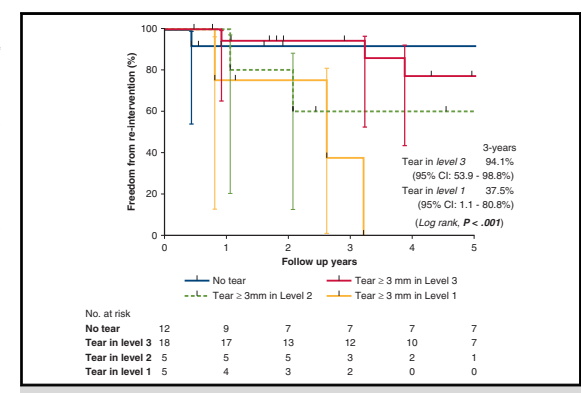

Kaplan-Meier curves of freedom from reintervention.

\section{Central Message}

Among the different locations for intimal tears in the residual TAA, those in the proximal DTA are the main cause of aortic dilation and reintervention.

\section{Perspective}

Understanding the differential impact of intimal tear location is important for predicting the fate of the residual TAA after TAR in AIAD. Intimal tears in the proximal DTA should be carefully evaluated; if needed, additional interventions should be considered.

See Commentaries on pages 339 and 341.

\footnotetext{
${ }^{a}$ Department of Medicine, Yonsei University Graduate School of Medicine, Seoul, Republic of Korea; ${ }^{\mathrm{b}}$ Department of Thoracic and Cardiovascular Surgery, Haeundae Paik Hospital, Inje University College of Medicine, Busan, Republic of Korea; ${ }^{c}$ Department of Cardiovascular Surgery, Gangnam Severance Hospital, Seoul, Republic of Korea; ${ }^{\mathrm{d}}$ Department of Cardiovascular Surgery, Yonsei Cardiovascular Hospital, Severance Hospital, Seoul, Republic of Korea; ${ }^{\mathrm{e}}$ The Korean Heart Foundation, Seoul, Republic of Korea; and ${ }^{\mathrm{f}}$ Biostatistics Collaboration Unit, Yonsei University College of Medicine, Seoul, Republic of Korea.

Institutional Review Board approval: Yonsei Institutional Review Board No. 3-20180063

Read at the 98th Annual Meeting of The American Association for Thoracic Surgery, San Diego, California, April 28-May 1, 2018.

Received for publication May 1, 2018; revisions received Aug 25, 2018; accepted for publication Sept 19, 2018; available ahead of print April 8, 2019.

Address for reprints: Suk-Won Song, MD, PhD, Department of Cardiovascular Surgery, Gangnam Severance Hospital, Yonsei University College of Medicine, 211 Enoju-ro, Gangnam-gu, Seoul 06273, Republic of Korea (E-mail: sevraphd@ yuhs.ac).

$0022-5223 / \$ 36.00$

Copyright (C) 2018 by The American Association for Thoracic Surgery

https://doi.org/10.1016/j.jtcvs.2018.09.110
}

After surgical repair of acute type I aortic dissection (AIAD) (Video 1), the residual thoracoabdominal aorta (TAA) remains dissected and may further develop aneurysms that require treatment.

The remnant intimal tears, either unapproachable for resection during initial open surgery or newly developed

Uf Scanning this QR code will
take you to the article title
page to access supplementary
information. To view the
AATS Annual Meeting Web-
cast, see the URL next to the
webcast thumbnail.




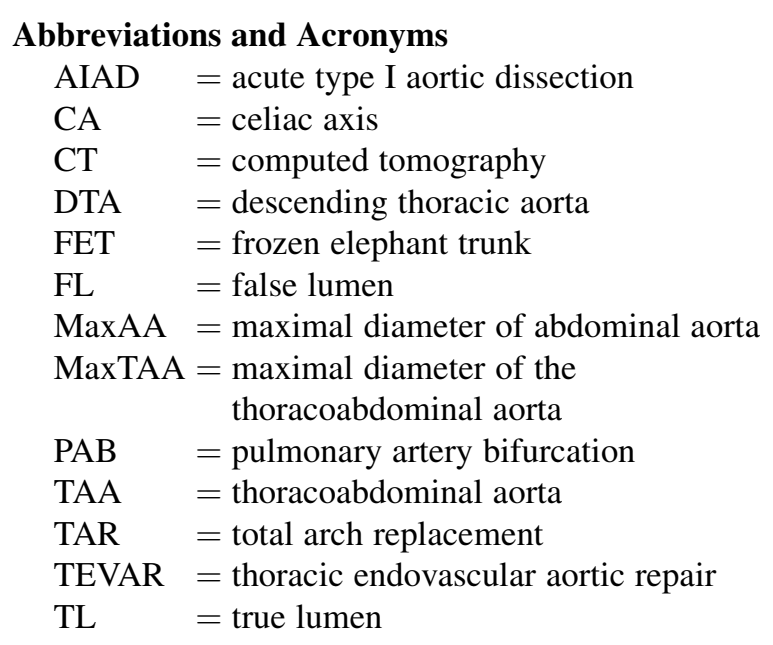

during follow-up, act as communicating channels between the true lumen (TL) and false lumen (FL) of the residual dissected TAA. Thus, a persistent pressurized FL may explain the aneurysmal change in the residual TAA after total arch replacement (TAR), ${ }^{2-4}$ and the size and location of intimal tears affect the FL status and its pressure. ${ }^{5,6}$

For unapproachable intimal tears in the proximal descending thoracic aorta (DTA), the frozen elephant trunk (FET) procedure is widely used to improve favorable aortic remodeling by covering the intimal tear to achieve depressurized FL. Several studies have proven the safety of the procedure, with acceptable outcomes. ${ }^{7-12}$ However, FET cannot prevent newly developed intimal tears. Further, regarding the indications for the FET procedure, the advantage of routinely performing FET is still questionable in cases of AIAD without an intimal tear in the proximal DTA.

In the present study, we hypothesized that the intimal tear in the proximal DTA after surgical repair of AIAD might be the most significant factor for aortic dilation and reintervention; further, if there were no intimal tears in the proximal DTA after AIAD repair, favorable aortic remodeling was achieved without the FET procedure.

\section{PATIENTS AND METHODS}

This study was approved by the Institutional Review Board of Gangnam Severance Hospital, Yonsei University College of Medicine (No. 3-20180063). Because of the retrospective nature of the study, the need for individual patient consent was waived.

\section{Study Population}

A retrospective review of the Gangnam Severance Aortic Registry identified 85 patients with AIAD who underwent TAR between 2009 and 2016. Before 2009, there were no specified aortic surgeons and the operative strategy was not standardized. After 2009, 1 aortic surgeon performed the operation in most cases, and the operative strategy has been consistent. Thus, we

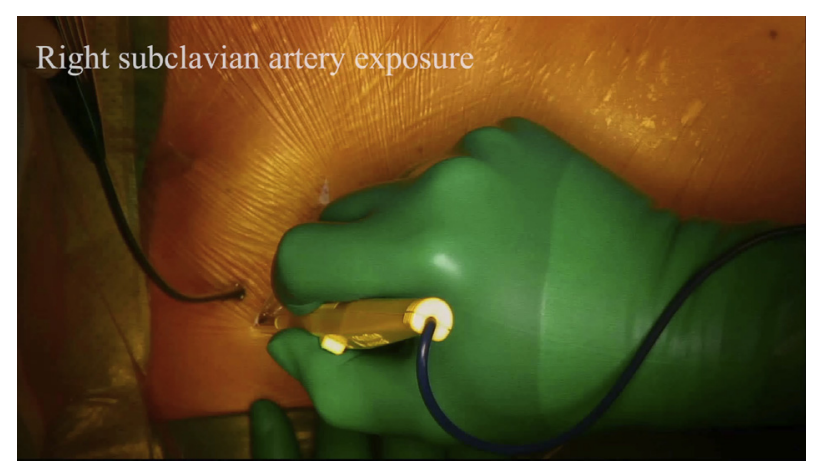

VIDEO 1. Total arch replacement for AIAD. Video available at: https:// www.jtcvs.org/article/S0022-5223(18)32654-0/fulltext.

only included patients after 2009. We excluded patients from after 2016 because we collected the data for this study in mid-2017, and at this point of time, patients who had undergone surgery in 2017 had not yet received a second postoperative computed tomography (CT) scan. Exclusion criteria were intramural hematoma or retrograde dissection $(\mathrm{n}=8)$, in-hospital death $(\mathrm{n}=14)$, intimal dissection ending above the mid-DTA ( $\mathrm{n}=3)$, Marfan syndrome $(\mathrm{n}=1)$, and the absence of a second postoperative follow-up CT scan $(n=19)$. Finally, 40 patients who underwent TAR $(n=26)$ or TAR via the FET procedure $(n=14)$ were enrolled in this study (Figure 1$)$. These patients underwent postoperative $\mathrm{CT}$ scans at least twice.

\section{Indications for the Frozen Elephant Trunk Procedure and Operative Strategy}

In patients with AIAD, the FET procedure was used in cases of reentry or penetrating atherosclerotic ulcers in the proximal DTA, aneurysmal change in the distal arch, and circumferential detachment of the adventitia. ${ }^{7,8}$ The size of the stent graft was selected according to preoperative and intraoperative measurements. The stent-graft diameter is estimated at $90 \%$ of the total aortic diameter at the level of the distal landing zone. The median diameter of the prosthesis used was $30 \mathrm{~mm}$ (interquartile

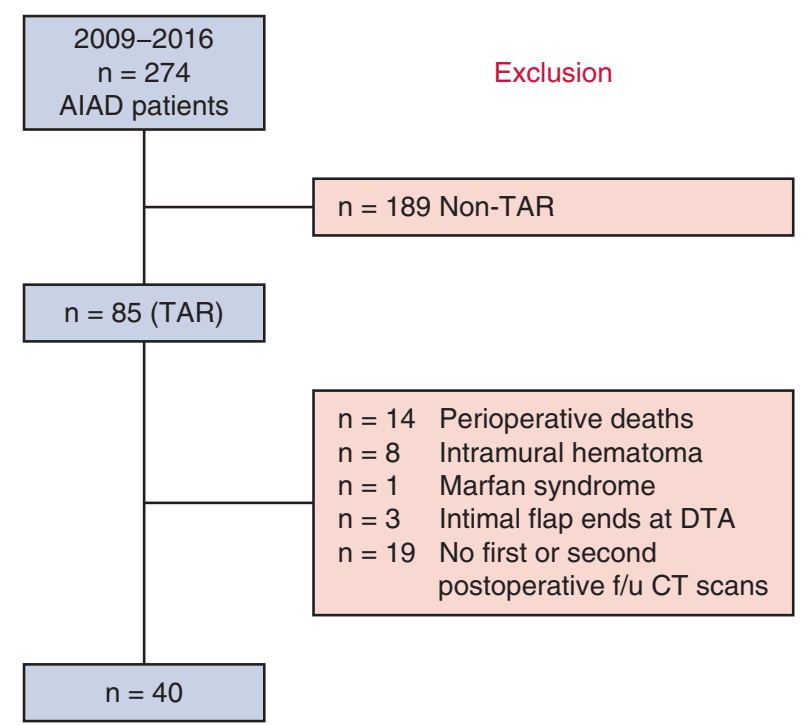

FIGURE 1. Flow of patient selection process. AIAD, Acute type I aortic dissection; TAR, total arch replacement; DTA, descending thoracic aorta; $f / u$, follow up; $C T$, computed tomography. 
range, 30-34 mm), and the median length was $130 \mathrm{~mm}$ (interquartile range, 120-150 mm, S\&G Biotech, Seongnam, Korea). The surgical method has been described previously. ${ }^{13,14}$

\section{Image Analysis}

Two observers performed the image analysis. Aortic diameter was measured by a single registered nurse; the intimal tear size, location, and false status were measured by a single medical doctor. Aortic diameter was measured at 4 different levels (pulmonary artery bifurcation [PAB], celiac axis [CA], maximal abdominal aorta [MaxAA], and maximal thoracoabdominal aorta [MaxTAA]) using serial follow-up CT scans. MaxAA was measured at the maximal diameter between the renal artery and the aortic bifurcation. The SYNAPSE 3D (Fujifilm Medical, Tokyo, Japan) was used to measure the MaxTAA and MaxAA and to identify intimal tears (Figure 2).

Intimal tear (size and number) and FL status (complete or not) were analyzed at 3 different levels (level 1: proximal DTA, from the distal anastomosis to the seventh thoracic vertebra; level 2: distal DTA, from the seventh thoracic vertebra to the $\mathrm{CA}$; level 3: abdominal aorta, from the CA to the aortic bifurcation) (Figure 3). Because the mean duration of the first postoperative follow-up CT scan ( $9.8 \pm 3.7$ days) was too short to evaluate the stabilization of the intimal flap, the variables regarding the intimal tear and anastomotic leak used in linear-mixed analysis were collected from the second follow-up CT scan (5.5 \pm 3.3 months).

Our standard aorta CT was performed with a 3-mm section thickness. This means that if a tear is seen on more than 2 sections, it indicates that the tear size is larger than $3 \mathrm{~mm}$. Additionally, if the tear size was more than $5 \mathrm{~mm}$ in a single axial plane of the CT image, we considered it as an intimal tear more than $5 \mathrm{~mm}$. Various limitations exist regarding this method; however, it was assumed that by the time the second CT scan follow-up was performed, the intimal tear had gained rigidity as it would have entered the chronic stage. The tear identification and size measurement were not technically difficult. The degree of FL status was analyzed using precontrast, arterial, and delayed-phase CT scans. We defined "complete thrombosis" as a state with no flow in the FL. In patients who underwent the FET procedure, the diameter at the PAB level was measured regardless of whether the stent covered the PAB level.

The aortic diameter and factors related to intimal tear and FL status were measured separately. Patients also underwent at least 2 to $8 \mathrm{CT}$ scans, and we measured each level of aortic diameter in every scan.

\section{Statistical Analysis}

Categoric variables were summarized using frequencies and percentages and were compared using the Fisher exact test or the chi-square test. Continuous variables were analyzed using the mean and standard deviation, with median and interquartile range, and compared using the independent $t$ test or Mann-Whitney $U$ test. The Shapiro-Wilk test was used to test for the normality of the distribution. The linear mixed model for a repeated-measures random intercept and slope model was used. The change of size according to time was considered as covariates $\times$ time interactions. All time was considered in month units. The time-related event was postoperative intervention. Freedom from time-related event was estimated using the Kaplan-Meier method and compared using the log-rank test.

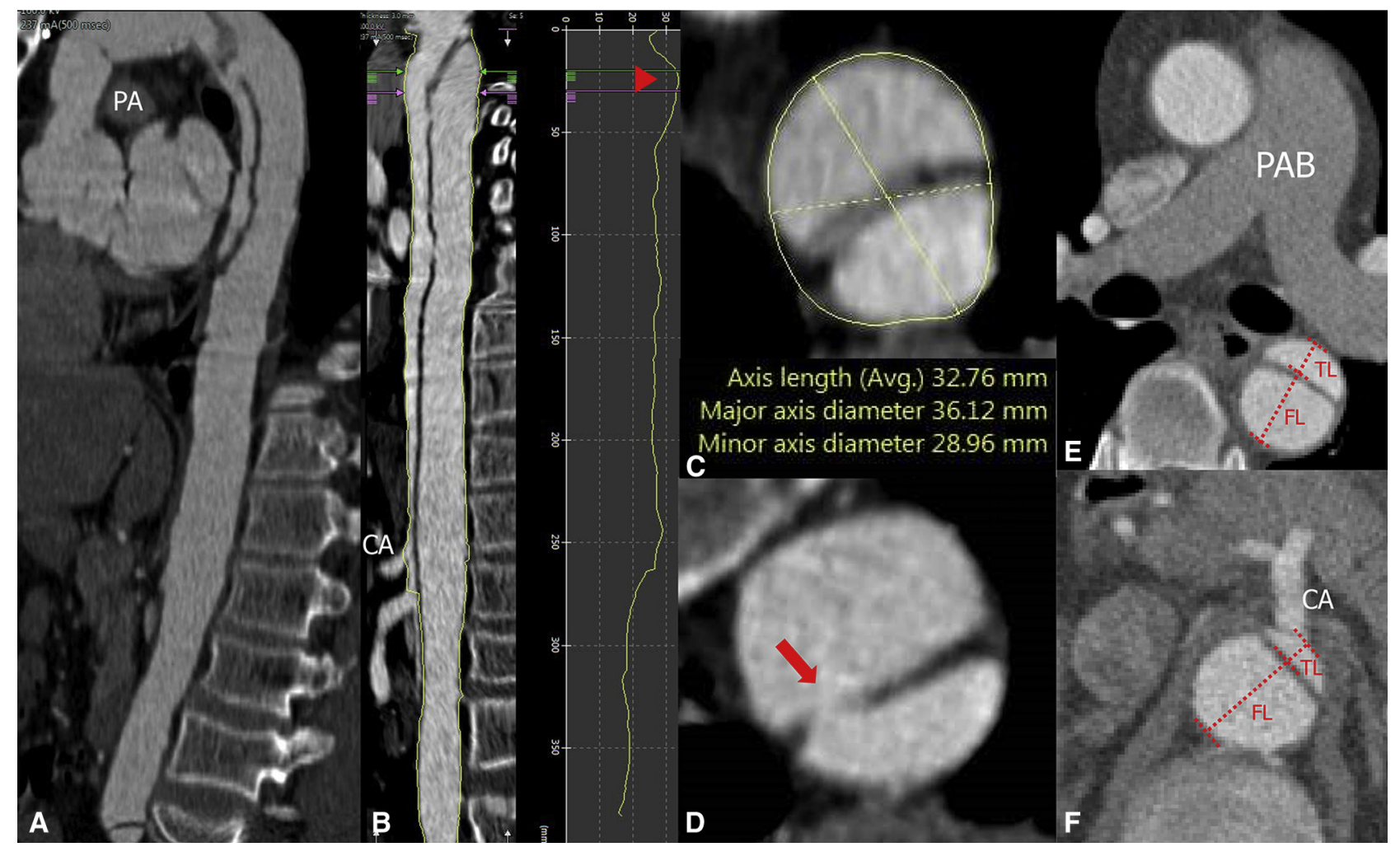

FIGURE 2. Measurement of the diameter of the aorta and identification of intimal tear at each level of the aorta using SYNAPSE 3D (Fujifilm Medical, Tokyo, Japan) and general CT scans. A and B, Reconstructed images of the sagittal and straightened aorta. Maximal diameter of the TAA (red wedge arrow). $\mathrm{C}$, The major axis diameter was measured. D, Intimal tear in the aorta (red arrow). E and F, Diameters at the PAB and CA levels were measured in the axial planes of the CT scans. The TL and FL at the PAB and CA and the MaxAA levels were also measured. PA, Pulmonary artery; $C A$, celiac axis; $P A B$, pulmonary artery bifurcation; $F L$, false lumen; $T L$, true lumen. 


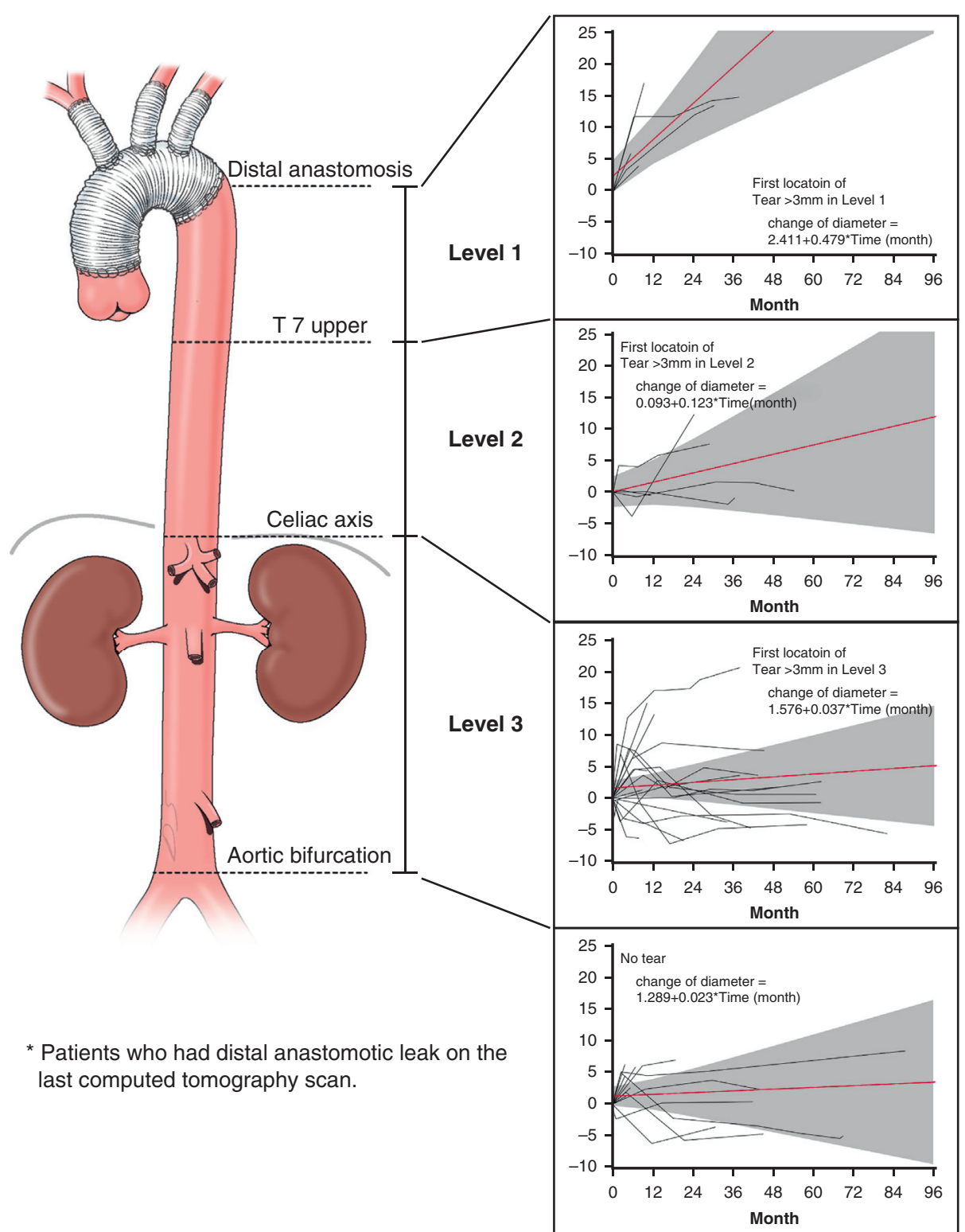

FIGURE 3. Levels 1 to 3 of the aorta and changes in maximal thoracoabdominal aortic diameter stratified according to the first location of intimal tear $3 \mathrm{~mm}$ or greater.

All statistical tests were 2-tailed. All statistical analyses were performed by Hye Sun Lee (Doctor of Philosophy in Statistics) using statistical software $\mathrm{R}$ version 3.3.1 (R Development Core Team) and SAS version 9.2 (SAS Inc, Cary, NC).

\section{RESULTS}

Table 1 summarizes the perioperative characteristics of the entire cohort and the subgroups.

\section{Overall Characteristic Changes in the Residual Thoracoabdominal Aorta}

The diameter of the residual aorta tended to increase over the follow-up period. The changes from the initial diameter at the level of the PAB were clearly separated into increasing and decreasing groups (Figure 4, A). The diameter of the TL at the PAB level showed an increasing trend (Figure 4, B), whereas the diameter of the FL at the $\mathrm{PAB}$ level showed a general decreasing trend; however, some patients showed an overall persistent increasing trend (Figure 4,C). This means that certain factors were influencing these trends. The changes in the diameter at the level of the CA showed trends similar to those in the changes at the level of the PAB, but the incremental or decremental difference was lower (Figure $4, D-F$ ). The diameter changes at the level of the MaxAA showed increasing trends, but the incremental differences were 
TABLE 1. Perioperative data

\begin{tabular}{|c|c|c|c|c|}
\hline Variables & Total $(n=40)$ & TAR $(n=26)$ & TAR with FET $(n=14)$ & $P$ value \\
\hline Age, $y$ & $50.4 \pm 12.1$ & $49.1 \pm 13.4$ & $52.9 \pm 9.1$ & .201 \\
\hline Male & $31(77.5 \%)$ & $19(73.1 \%)$ & $12(85.7 \%)$ & .606 \\
\hline Body mass index $\left(\mathrm{kg} / \mathrm{m}^{2}\right)$ & $24.6 \pm 3.4$ & $24.6 \pm 3.6$ & $24.5 \pm 3.1$ & .950 \\
\hline Duration of follow up (mo) & $50.8 \pm 29.1$ & $50.7 \pm 32.1$ & $51.1 \pm 23.4$ & .966 \\
\hline \multicolumn{5}{|c|}{ Postoperative CT follow-up interval (mo) } \\
\hline First to second & $5.5 \pm 3.3$ & $5.8 \pm 3.0$ & $5.1 \pm 4.0$ & .579 \\
\hline First to last & $32.8 \pm 23.4$ & $32.7 \pm 24.5$ & $33.1 \pm 22.0$ & .865 \\
\hline Hypertension & $25(62.5 \%)$ & $14(53.8 \%)$ & $11(78.6 \%)$ & .231 \\
\hline Diabetes mellitus & $2(5.0 \%)$ & $1(3.8 \%)$ & $1(7.1 \%)$ & 1.00 \\
\hline History of cerebral stroke & $2(5.0 \%)$ & $1(3.8 \%)$ & $1(7.1 \%)$ & 1.00 \\
\hline \multicolumn{5}{|l|}{ Preoperative laboratory finding } \\
\hline Serum creatinine $(\mathrm{mg} / \mathrm{dL})$ & $1.0 \pm 0.3$ & $1.0 \pm 0.3$ & $0.9 \pm 0.3$ & .705 \\
\hline Serum creatinine $>1.5 \mathrm{mg} / \mathrm{dL}$ & $3(7.5 \%)$ & & & \\
\hline Hemoglobin (g/dL) & $13.5 \pm 1.8$ & $13.3 \pm 2.0$ & $13.7 \pm 1.2$ & .446 \\
\hline Bentall procedure & $3(7.5 \%)$ & $3(11.5 \%)$ & $0(0 \%)$ & .489 \\
\hline \multicolumn{5}{|l|}{ Graft } \\
\hline Graft size (mm) & $28.2 \pm 2.6$ & $27.8 \pm 2.7$ & $28.9 \pm 2.4$ & .193 \\
\hline Stent-graft diameter (mm) & & & $31.7 \pm 4.1$ & \\
\hline Stent-graft length (mm) & & & $127.1 \pm 18.6$ & \\
\hline Total operation time (min) & $346.7 \pm 84.6$ & $365.1 \pm 84.4$ & $312.4 \pm 76.4$ & .059 \\
\hline Ventilator (h) & $17.5 \pm 20.7$ & $18.0 \pm 25.0$ & $16.5 \pm 9.4$ & .321 \\
\hline ICU stay (h) & $66.6 \pm 47.6$ & $59.4 \pm 28.8$ & $80.0 \pm 70.1$ & .932 \\
\hline Hospital stay (d) & $19.8 \pm 11.3$ & $17.7 \pm 9.0$ & $23.8 \pm 14.2$ & .147 \\
\hline
\end{tabular}

lower than those observed at the level of the CA (Figure 4, $G-I)$.

In the first, second, and last follow-up CT scans, 30 $(75 \%), 36(90 \%)$, and $36(90 \%)$ patients, had 69, 102, and 104 intimal tears, respectively.

In the second and last follow-up CT scans, complete thrombosis was observed in $42.5 \%, 7.5 \%$, and $5.3 \%$ and in $60.0 \%, 32.5 \%$, and $7.9 \%$ at levels 1,2 , and 3 , respectively.

The follow-up intervals from the first to the second and from the first to the last CT scans were $5.5 \pm 3.3$ months and $32.8 \pm 23.4$ months, respectively. During the followup period between the second and the last CT scan, the number of intimal tears did not change significantly.

\section{Changes in Aortic Diameter and False Lumen Status According to the Location of Intimal Tears ( $\geq \mathbf{3 ~ m m}$ )}

Table E1 shows the comparison of the groups. In the first follow-up CT scans, the TL at the PAB level with the first tear at level 1 had the smallest diameter with statistical significance $(P=.023)$. In contrast, the FL at the PAB level had the largest diameter yet, with no statistical significance.
In the last follow-up CT scans, the smallest diameter in the TL at the PAB level $(P=.020)$ and the largest diameter in the FL at the PAB level $(P=.004)$ were seen in patients with the first tear at level 1. In addition, the MaxTAA diameter was largest in the level 1 zone, but this difference was not statistically significant.

The overall diameter growth rate at the PAB level was the highest in patients with the first tear at level 1 . The change in the TL was minimal, but the increase in FL diameter was the highest among the groups.

Twenty-four patients achieved complete thrombosis of the FL at level 1. None of the patients with the first tear at level 1 achieved complete thrombosis of the FL (Table E2), and the overall rate of achieving complete thrombosis was significantly lower $(P=.031)$.

\section{Changes in Aortic Diameter and False Lumen Status With or Without Frozen Elephant Trunk Procedure}

Tables E3 and E4 show the comparison of the 2 groups. In the first follow-up CT scans, larger TL and smaller FL at the PAB level were seen in the FET group with statistical significance. This was most likely the stent-graft effect on TL. 


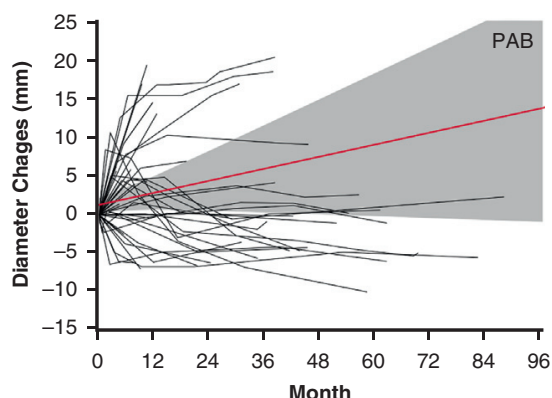

A

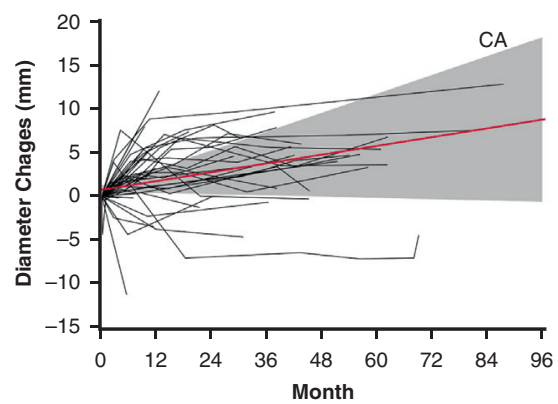

D

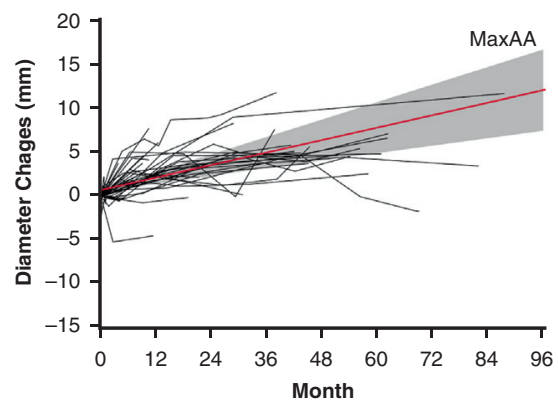

G

FIGURE 4. Linear mixed analysis of aortic diameter. A-C, Aortic diameter changes of PAB level, TL, and FL of the PAB level. D-F, Aortic diameter changes of CA level, TL and FL of the PAB level. G-I, Aortic diameter changes of MaxAA level, TL and FL of the PAB level. PAB, Pulmonary artery bifurcation; $T L$, true lumen; $F L$, false lumen; $C A$, celiac axis; MaxAA, maximal diameter of abdominal aorta.

However, in the last follow-up CT scans, there were no statistically significant differences between the 2 groups.

The growth rate of the TL at the PAB level was highest in the non-FET group $(P=.003)$. Both groups reached similar point in terms of growth diameter, but at different growth rates.

\section{Linear Mixed Analysis (Random Intercept and Slope Model)}

The use of FET and the presence of intimal tears $(\geq 3$ and $\geq 5 \mathrm{~mm}$ ) were not significant factors influencing aortic dilation. Distal anastomotic leak $(n=7)$ was the significant factor for increasing the MaxAA level. We thought that this result was associated with the location of intimal tears. Among these patients, 4 had intimal tears $(\geq 3 \mathrm{~mm}, \mathrm{n}=2$; $\geq 5 \mathrm{~mm}, \mathrm{n}=2$ ) at the abdominal aorta (level 3). Intimal tears at level 1 were significantly associated with aortic dilation (PAB, CA, MaxAA, and MaxTAA levels). Compared with the first location of intimal tears $(\geq 3 \mathrm{~mm})$ at level 3 , the beta values of aortic level 1 at the PAB, CA, MaxAA, and MaxTAA levels were 0.609 (0.211), 0.277 (0.120), and 0.496 (0.188), respectively (Table 2) (Figure 3 ).

The adjusted model showed that the most significant factor for increasing MaxTAA was the intimal tear at the level 1 (first location of intimal tear level 1 , beta $=0.400$ [0.102], $P<.001$ ) (Table 3). The number of visceral branches originating from the FL was also a significant factor.

\section{Rate of Freedom From Reintervention According to the First Location of the Intimal Tear}

Ten patients $(25 \%)$ underwent reintervention. Among the patients with intimal tears $(\geq 3 \mathrm{~mm})$ at level 1,4 
TABLE 2. Linear mixed-model analysis of the interaction between variables

\begin{tabular}{|c|c|c|c|c|c|c|c|c|}
\hline \multirow[b]{2}{*}{ Variables } & \multicolumn{2}{|l|}{ PAB } & \multicolumn{2}{|l|}{ CA } & \multicolumn{2}{|l|}{ MaxAA } & \multicolumn{2}{|c|}{ MaxTAA } \\
\hline & B (SE) & $\overline{P \text { value }}$ & B (SE) & $\overline{P \text { value }}$ & B (SE) & $\overline{P \text { value }}$ & B (SE) & $\overline{P \text { value }}$ \\
\hline Diameter of PAB level (first postoperative CT) & $0.014(0.012)$ & .252 & $0.012(0.007)$ & .091 & $0.001(0.004)$ & .765 & $0.012(0.010)$ & .263 \\
\hline No. of visceral branches from FL & $0.059(0.030)$ & .052 & $0.041(0.021)$ & .057 & $0.037(0.015)$ & .015 & $0.055(0.023)$ & .019 \\
\hline No. of identified intimal tear (any size) & $0.001(0.015)$ & .960 & $0.002(0.005)$ & .649 & $0.006(0.006)$ & .349 & $-0.000(0.013)$ & .976 \\
\hline FET $(n=14)$ & $0.005(0.108)$ & .967 & $0.007(0.060)$ & .907 & $-0.008(0.051)$ & .878 & $-0.052(0.088)$ & .558 \\
\hline Distal anastomotic leak $(\mathrm{n}=7)$ & $0.259(0.168)$ & .125 & $0.109(0.108)$ & .312 & $0.111(0.024)$ & $<.001$ & $0.094(0.149)$ & .531 \\
\hline Presence of intimal tear $>3 \mathrm{~mm}(\mathrm{n}=26)$ & $-0.053(0.109)$ & .632 & $0.068(0.059)$ & .257 & $0.082(0.051)$ & .108 & $-0.001(0.094)$ & .993 \\
\hline Presence of intimal tear $>5 \mathrm{~mm}(\mathrm{n}=13)$ & $-0.054(0.108)$ & .614 & $0.094(0.063)$ & .141 & $0.073(0.052)$ & .166 & $0.035(0.093)$ & .708 \\
\hline \multicolumn{9}{|l|}{ Location of intimal tear $>3 \mathrm{~mm}$} \\
\hline Level $1(\mathrm{n}=5)$ & $0.603(0.199)$ & .003 & $0.308(0.111)$ & .007 & $0.105(0.077)$ & .172 & $0.483(0.179)$ & .008 \\
\hline Level $2(\mathrm{n}=7)$ & $0.053(0.139)$ & .707 & $0.084(0.086)$ & .333 & $0.053(0.076)$ & .484 & $0.177(0.115)$ & .127 \\
\hline Level $3(n=22)$ & $-0.082(0.101)$ & .419 & $0.060(0.058)$ & .299 & $0.056(0.049)$ & .257 & $-0.091(0.088)$ & .304 \\
\hline \multicolumn{9}{|l|}{ Location of intimal tear $>5 \mathrm{~mm}$} \\
\hline Level $1(n=2)$ & $1.161(0.376)$ & .003 & $0.860(0.243)$ & .001 & $0.330(0.159)$ & .040 & $1.117(0.341)$ & .002 \\
\hline & $0.077(0.147)$ & .602 & $0.139(0.091)$ & .132 & $0.155(0.079)$ & .051 & $0.216(0.120)$ & .076 \\
\hline Level $3(n=11)$ & $-0.082(0.118)$ & .487 & $0.153(0.064)$ & .019 & $0.109(0.052)$ & .036 & $-0.010(0.103)$ & .924 \\
\hline \multicolumn{9}{|l|}{$\begin{array}{l}\text { First location of intimal tear }>3 \mathrm{~mm} \text { (Beta is based on } \\
\text { level 3) }\end{array}$} \\
\hline Level $1(\mathrm{n}=5)$ & $0.609(0.211)$ & .005 & $0.277(0.120)$ & .023 & $0.066(0.077)$ & .389 & $0.442(0.131)$ & .001 \\
\hline Level $2(n=5)$ & $-0.059(0.142)$ & .679 & $-0.059(0.078)$ & .455 & $-0.076(0.083)$ & .361 & $0.087(0.105)$ & .414 \\
\hline Level $3(n=18)$ & $0.000()$. & . & $0.000()$. & . & $0.000()$. & . & $0.000()$. & . \\
\hline No intimal tear $(n=12)$ & $0.067(0.109)$ & .543 & $-0.098(0.058)$ & .095 & $-0.099(0.053)$ & .064 & $-0.014(0.081)$ & .866 \\
\hline \multicolumn{9}{|l|}{$\begin{array}{l}\text { First location of intimal tear }>5 \mathrm{~mm} \text { (Beta is based on } \\
\text { level 3) }\end{array}$} \\
\hline Level $1(n=2)$ & $1.260(0.391)$ & .002 & $0.816(0.251)$ & .002 & $0.314(0.167)$ & .063 & $1.205(0.353)$ & .001 \\
\hline Level $2(n=4)$ & $0.014(0.176)$ & 935 & $-0.034(0.097)$ & .731 & $0.061(0.104)$ & .556 & $0.166(0.150)$ & .270 \\
\hline $\mathrm{n}=7)$ & $0.000()$. & . & $0.000()$. & . & $0.000()$. & & $0.000()$. & . \\
\hline No intimal tear $(\mathrm{n}=27)$ & $0.136(0.127)$ & .286 & $-0.056(0.070)$ & .420 & $-0.029(0.06)$ & .629 & $0.099(0.108)$ & .363 \\
\hline
\end{tabular}

Bold indicates $P<.05$. PAB, Pulmonary artery bifurcation; $C A$, celiac axis; MaxAA, maximal diameter of abdominal aorta; MaxTAA, maximal diameter of thoracoabdominal aorta; $B$, beta; $S E$, standard error; $C T$, computed tomography; $F L$, false lumen; $F E T$, frozen elephant trunk.

$(80 \%)$ underwent reintervention (zone 2 thoracic endovascular aortic repair [TEVAR], $\mathrm{n}=1$; zone 3 TEVAR, $\mathrm{n}=2$; FL procedure at the DTA, $\mathrm{n}=1)$. Among the patients with intimal tears $(\geq 3 \mathrm{~mm})$ at level 2, $2(40 \%)$ underwent reintervention (zone 4 TEVAR, $\mathrm{n}=2$ ). Among the patients with intimal tears $(\geq 3 \mathrm{~mm})$ at level 3,3 $(16.7 \%$ ) underwent reintervention (zone 3 TEVAR for distal anastomotic leak, $\mathrm{n}=2$; TAA replacement, $\mathrm{n}=1)$. Among the patients with no intimal tear, 1 $(8.3 \%)$ underwent reintervention (zone 3 TEVAR for distal anastomotic leak) (Table E5). The rate of 3-year freedom from reintervention was $94.1 \%$ in patients with intimal tears $(\geq 3 \mathrm{~mm})$ at level 3 and $37.5 \%$ in patients with intimal tears greater than $3 \mathrm{~mm}$ at level 1 (logrank, $P<.001$ ) (Figure 5).

Among the patients who underwent FET, 3 (21\%) underwent reintervention (zone 3 TEVAR for distal anastomotic leakage, $\mathrm{n}=1$; zone 3 TEVAR for level 1 intimal tear, $\mathrm{n}=1$; zone 4 TEVAR for level 2 intimal tear, $\mathrm{n}=1$ ). There were no significant differences between the non-FET and FET groups (Table E6).

Among the patients who had distal anastomotic leaks as per their last CT scans, $4(100 \%)$ underwent reintervention (zone 3 TEVAR, $\mathrm{n}=3$; TAA replacement, $\mathrm{n}=1$ ).

\section{DISCUSSION}

We confirmed that intimal tears at level 1 were the most significant factor affecting aortic dilation and reintervention. Among the patients who had intimal tears at level 1, none achieved complete thrombosis at any aortic level. We believe that the hemodynamic changes and hemostatic disturbance may have influenced this outcome. Bonfanti and colleagues ${ }^{15}$ reported that peak systolic pressure was observed at the intimal tear in the proximal DTA. By using computational fluid dynamics, they demonstrated that blood flowing through the entry tear impinges on the FL wall, causing a localized pressure increase and potentially leading to further enlargement/rupture of the FL wall. 
TABLE 3. Diameter change of maximal diameter of thoracoabdominal aorta using the linear mixed model (random intercept and slope model)

\begin{tabular}{|c|c|c|c|c|}
\hline \multirow[b]{2}{*}{ Variables } & \multicolumn{2}{|c|}{ Unadjusted model } & \multicolumn{2}{|c|}{ Adjusted model } \\
\hline & B (SE) & $P$ value & B (SE) & $P$ value \\
\hline Diameter of PAB level (first postoperative CT) & $0.012(0.010)$ & .263 & & \\
\hline No. of visceral branches from FL & $0.055(0.023)$ & .019 & $0.062(0.019)$ & .002 \\
\hline No. of intimal tears & $-0.001(0.013)$ & .976 & & \\
\hline FET & $-0.052(0.088)$ & .558 & & \\
\hline Distal anastomotic leak & $0.094(0.126)$ & .531 & & \\
\hline Presence of intimal tear $>3 \mathrm{~mm}$ & $-0.001(0.094)$ & .993 & & \\
\hline Presence of intimal tear $>5 \mathrm{~mm}$ & $0.035(0.093)$ & .708 & & \\
\hline \multicolumn{5}{|l|}{ Location of intimal tear $\geq 3 \mathrm{~mm}$} \\
\hline Level 1 & $0.483(0.179)$ & .008 & & \\
\hline Level 2 & $0.177(0.115)$ & .127 & & \\
\hline Level 3 & $-0.091(0.088)$ & .304 & & \\
\hline \multicolumn{5}{|l|}{ Location of intimal tear $\geq 5 \mathrm{~mm}$} \\
\hline Level 1 & $1.117(0.341)$ & .002 & & \\
\hline Level 2 & $0.216(0.120)$ & .076 & & \\
\hline Level 3 & $-0.010(0.103)$ & .924 & & \\
\hline \multicolumn{5}{|c|}{ First location of intimal tear $\geq 3 \mathrm{~mm}$ (comparing with level 3) } \\
\hline Level 1 & $0.442(0.131)$ & .001 & $0.400(0.102)$ & $<.001$ \\
\hline Level 2 & $0.087(0.105)$ & .414 & $0.038(0.083)$ & .645 \\
\hline Level 3 & $\operatorname{Ref}(0)$ & & $\operatorname{Ref}(0)$ & \\
\hline No intimal tear & $-0.014(0.081)$ & .866 & $0.037(0.058)$ & .525 \\
\hline \multicolumn{5}{|c|}{ First location of intimal tear $\geq 5 \mathrm{~mm}$ (comparing with level 3) } \\
\hline Level 1 & $1.205(0.353)$ & .001 & & \\
\hline Level 2 & $0.166(0.150)$ & .270 & & \\
\hline Level 3 & $\operatorname{Ref}(0)$ & & & \\
\hline No intimal tear & $0.099(0.108)$ & .363 & & \\
\hline
\end{tabular}

They also demonstrated that the proximal DTA had a higher blood flow rate than the abdominal aorta. ${ }^{15}$ However, this was not enough to understand the various locations and sizes of intimal tear, based on this study design. However, they showed that the amount of blood flow and blood pressure varied at different aortic levels and provided reasonable explanations regarding the progression of the dissected aorta.

Intimal tears at level 1 were a significant cause of aneurysmal change in the thoracic aorta. Therefore, for patients with intimal tears in the proximal DTA, performing TAR and concomitant FET procedures at the initial operation might be promising. Several studies have proven the safety of the FET procedure, with acceptable outcomes. ${ }^{7-12} \mathrm{Ma}$ and colleagues ${ }^{16}$ reported that TAR via the FET procedure can be safely performed even in patients with Marfan syndrome. In addition, by performing the FET procedure, immediate hemodynamic stability with central repair of the proximal DTA is expected, and favorable aortic remodeling with complete thrombosis in the FL is expected in the long term. Vallabhajosyula and colleagues ${ }^{17,18}$ reported that antegrade TEVAR aiding in concrete central repair may provide favorable aortic remodeling and survival benefits, especially in patients with distal multiorgan malperfusion. In our study, the FET group showed a rapid increase in the diameter of the TL at the PAB level compared with the non-FET groups in the early phase when the first CT was performed; this is most likely because of the stentgraft effect on TL.

Regarding the intimal tears identified preoperatively or intraoperatively, the FET procedure can be performed, but new intimal tears may develop in the residual dissected aorta during clinical follow-up. Rylski and colleagues ${ }^{3}$ reported that new intimal tears (not observed on the predischarge CT scans) were predominantly observed in the proximal DTA $(22 \%)$ and at the lesser curvature of aortic arch $(11 \%)$. In our study, $9(\geq 3 \mathrm{~mm}, \mathrm{n}=2)$ intimal tears were observed at level 1 during the first follow-up CT, and $13(\geq 3 \mathrm{~mm}, \mathrm{n}=5)$ intimal tears were observed at level 1 during the second follow-up CT. These 5 patients accounted for $12.5 \%$ of all the patients, and 4 patients did not undergo the FET procedure. For these 4 patients, the FET procedure at the initial operation may have been prophylactic and may have prevented the formation of intimal 


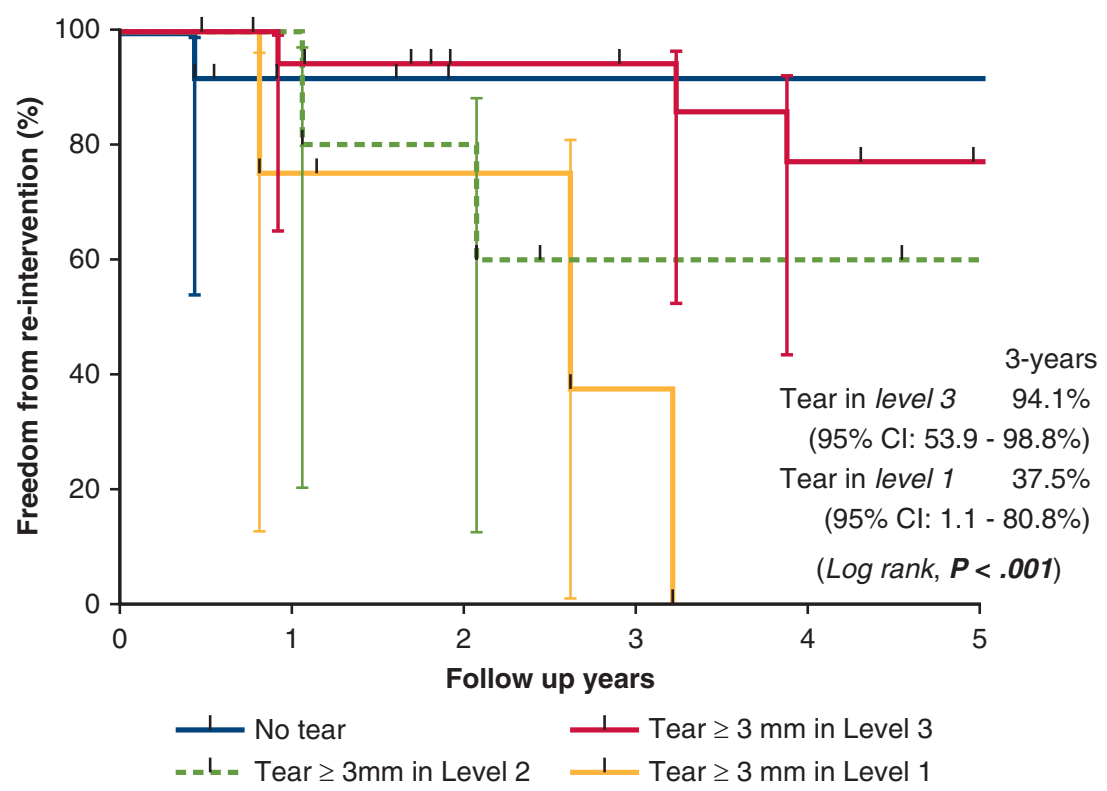

No. at risk

$\begin{array}{lcccccc}\text { No tear } & 12 & 9 & 7 & 7 & 7 & 7 \\ \text { Tear in level 3 } & 18 & 17 & 13 & 12 & 10 & 7 \\ \text { Tear in level 2 } & 5 & 5 & 5 & 3 & 2 & 1 \\ \text { Tear in level 1 } & 5 & 4 & 3 & 2 & 0 & 0\end{array}$

FIGURE 5. Kaplan-Meier curves of freedom from reintervention. $C I$, Confidence interval.

tears at the proximal DTA. However, it is uncertain if the intimal tears were newly developed or unidentified residual tears in a chronic state. One patient did undergo the FET procedure, but an intimal tear was found at level 1 at the location beyond the distal end of the graft (not a stentgraft-induced new entry). If a new level 1 tear was found during the post-TAR follow-up period, a retrograde TEVAR should suffice; therefore, we believe that the FET procedure is not mandatory for those without proximal DTA intimal tears in preoperative evaluation. In our study, there were no differences in the reintervention rate seen in the nonFET and FET groups. FET cannot cover up to level 2 tears. Additionally, stent graft-induced new entry or distal anastomotic leak can also occur. Therefore, no matter how FET is performed, there is a possibility of reintervention. In the FET group, the reintervention rate was $21.4 \%$. Roselli and colleagues ${ }^{12}$ reported that 10 patients $(13.9 \%)$ underwent reintervention among the patients with surgical repair with FET procedure in AIAD. Their reintervention rate was lower than in our study; however, the different indications for reintervention and shorter follow-up durations may have affected this difference.

In terms of aortic remodeling after the FET procedure in patients with AIAD, a recent study reported that mid-DTA FL thrombosis occurred in $99.3 \%$ subjects. ${ }^{19}$ However, this cohort included patients with acute type I and II (Stanford type A) and chronic aortic dissection. Therefore, the investigated result was limited to yield a solid analytical conclusion. Iafrancesco and colleagues ${ }^{19}$ reported that, beyond the mid-DTA, the FL thrombus formation rate at the level of the distal DTA, celiac trunk, and abdominal aorta was $52.6 \%, 24.8 \%$, and $13.9 \%$, respectively. It was apparent that the aortic remodeling rate was neither consistent nor favorably satisfying in the distal aorta beyond the stent-graft-covered area. In our study, there was no difference in the rate of complete thrombosis of the FL between the non-FET and FET groups (Table E4). In another study on FET with bare metal stenting of distal TAA, ${ }^{10} 62.5 \%(5 / 8)$ of patients achieved complete thrombosis in the abdominal aorta. The authors termed it the "Provisional Extension to Induce Complete Attachment" technique. This technique seems to be feasible and promising, but further study and follow-up are required.

Among the patients who had the intimal tears $(\geq 3 \mathrm{~mm}$ ) at level $1(\mathrm{n}=5), 4(80 \%)$ underwent reintervention. Interestingly, the remaining patient $(\mathrm{n}=1)$ had 6 intimal tears $5 \mathrm{~mm}$ or greater (level $1, \mathrm{n}=1$; level $2, \mathrm{n}=2$; level $3, \mathrm{n}=3$ ), but did not undergo reintervention, and the MaxTAA was $30.1 \mathrm{~mm}$. We believe that it was the feature of the patent FL with large reentry tears at level 3 that kept the systolic and diastolic blood pressures of the FL similar to the pressures in the TL, a fact that was also discussed by Tsai and colleagues. ${ }^{20}$ 
We believe that computational fluid dynamic simulation is expected to play a major role in understanding the hemodynamics of aortic dissection. This will enable us to understand the interactions between blood pressure or shear stress on the aortic wall and factors such as development of a new intimal tear, changes in the blood flow, and intimal flap movement. Further studies using computational fluid dynamic are needed.

\section{Study Limitations}

First, this is a retrospective design with a relatively small number of patients. Second, we did not review CT images taken at the same interval after surgery. Third, we could not compare the results of different sizes of intimal tears ( $\geq 10 \mathrm{~mm}$ ) because of the relatively small number of patients. Such comparison regarding different sizes of intimal tears might have shown more implications for the relationship between aortic dilation and the features of intimal tears in the residual TAA. Fourth, patients with level 1 tears showed relatively poorer aortic remodeling; almost all the patients who underwent FET and did not have level 1 tears showed better aortic remodeling. The linear-mixed analysis without FET group showed similar results that the beta value in patients with first location of intimal tear in level 1 ( $\mathrm{n}=4,0.304$ [0.135], $P=.028)$ and $2(\mathrm{n}=1,0.541$ [0.243], $P=.030$ ) had a statistical significance. However, the beta value of the first location of intimal tear in level 2 was larger than in level 1 , and we thought it was due to the influence of small sample size. Further study will be needed. Finally, preoperative aortic diameters were not evaluated. The quality and format of preoperative CT images taken at different referring hospitals were inappropriate for analysis.

\section{CONCLUSIONS}

We confirmed a more rapid increase in the diameter of the residual TAA in patients with an intimal tear at the proximal DTA. Furthermore, complete thrombosis at the proximal DTA was not achieved in these patients. Intimal tears in the proximal DTA should be carefully evaluated, because additional interventions might be needed.

\section{Webcast}

You can watch a Webcast of this AATS meeting presentation by going to: https://aats.blob.core.windows.net/media/ 18May01/28ABC\%202.Aortic\%20Endovascular/S85\%20\%20Part\%201/S85_1_webcast_020142893.mp4.

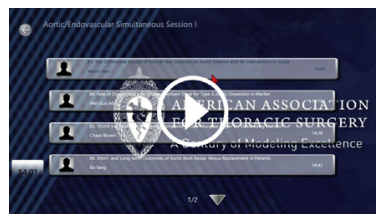

\section{Conflict of Interest Statement}

Authors have nothing to disclose with regard to commercial support.

The authors thank Dong-Su Jang (medical illustrator) for help with the illustrations.

\section{References}

1. Omura A, Miyahara S, Yamanaka K, Sakamoto T, Matsumori M, Okada K, et al. Early and late outcomes of repaired acute DeBakey type I aortic dissection after graft replacement. J Thorac Cardiovasc Surg. 2016;151:341-8.

2. Park K-H, Lim C, Choi JH, Chung E, Choi SI, Chun EJ, et al. Midterm change of descending aortic false lumen after repair of acute type I dissection. Ann Thorac Surg. 2009;87:103-8.

3. Rylski B, Hahn N, Beyersdorf F, Kondov S, Wolkewitz M, Blanke P, et al. Fate of the dissected aortic arch after ascending replacement in type A aortic dissection. Eur J Cardiothorac Surg. 2017;51:1127-34.

4. Heo W, Song SW, Lee KH, Lee SY, Kim TH, Baek MY, et al. Surgery for acute Type I aortic dissection without resection of supra-aortic entry sites leads to unfavourable aortic remodelling. Eur J Cardiothorac Surg. 2018;54:34-41.

5. Tsai TT, Schlicht MS, Khanafer K, Bull JL, Valassis DT, Williams DM, et al. Tear size and location impacts false lumen pressure in an ex vivo model of chronic type B aortic dissection. J Vasc Surg. 2008;47:844-51.

6. Girish A, Padala M, Kalra K, McIver BV, Veeraswamy RK, Chen EP, et al. The impact of intimal tear location and partial false lumen thrombosis in acute type B aortic dissection. Ann Thorac Surg. 2016;102:1925-32.

7. Liu ZG, Sun LZ, Chang Q, Zhu JM, Dong C, Yu CT, et al. Should the "elephant trunk" be skeletonized? Total arch replacement combined with stented elephant trunk implantation for Stanford type A aortic dissection. J Thorac Cardiovasc Surg. 2006;131:107-13.

8. Shrestha M, Bachet J, Bavaria J, Carrel TP, De Paulis R, Di Bartolomeo R, et al. Current status and recommendations for use of the frozen elephant trunk technique: a position paper by the vascular domain of EACTS. Eur J Cardiothorac Surg. 2015;47:759-69.

9. Shrestha M, Beckmann E, Krueger H, Fleissner F, Kaufeld T, Koigeldiyev N, et al. The elephant trunk is freezing: the Hannover experience. J Thorac Cardiovasc Surg. 2015;149:1286-93.

10. Hsu HL, Chen YY, Huang CY, Huang JH, Chen JS. The provisional extension to induce complete attachment (PETTICOAT) technique to promote distal aortic remodelling in repair of acute DeBakey type I aortic dissection: preliminary results. Eur J Cardiothorac Surg. 2016;50:146-52.

11. Takagi H, Umemoto T, ALICE Group. A meta-analysis of total arch replacement with frozen elephant trunk in acute type A aortic dissection. Vasc Endovasc Surg. 2016;50:33-46.

12. Roselli EE, Idrees JJ, Bakaeen FG, Tong MZ, Soltesz EG, Mick S, et al. Evolution of simplified frozen elephant trunk repair for acute DeBakey type I dissection: midterm outcomes. Ann Thorac Surg. 2018;105:749-55.

13. Song SW, Yoo KJ, Shin YR, Lim SH, Cho BK. Effects of intermittent lower body perfusion on end-organ function during repair of acute DeBakey type I aortic dissection under moderate hypothermic circulatory arrest. Eur J Cardiothorac Surg. 2013;44:1070-5.

14. Choi HY, Song SW, Hong SC, Lim SH. Total arch replacement with stented elephant trunk in DeBakey type I acute aortic dissection. Korean J Thorac Cardiovasc Surg. 2013;46:68-71.

15. Bonfanti M, Balabani S, Greenwood JP, Puppala S, Homer-Vanniasinkam S, Diaz-Zuccarini V. Computational tools for clinical support: a multi-scale compliant model for haemodynamic simulations in an aortic dissection based on multi-modal imaging data. J R Soc Interface. 2017;14(136).

16. Ma W-G, Zhang W, Zhu J-M, Ziganshin BA, Zhi A-H, Zheng J, et al. Long-term outcomes of frozen elephant trunk for type A aortic dissection in patients with Marfan syndrome. J Thorac Cardiovasc Surg. 2017;154:1175-89.e2.

17. Vallabhajosyula P, Gottret JP, Robb JD, Szeto WY, Desai ND, Pochettino A, et al. Hemiarch replacement with concomitant antegrade stent grafting of the descending thoracic aorta versus total arch replacement for treatment of acute DeBakey I aortic dissection with arch tear. Eur J Cardiothorac Surg. 2016;49:1256-61; discussion 61.

18. Vallabhajosyula P, Gottret JP, Menon R, Sultan I, Abbas Z, Siki M, et al. Central repair with antegrade TEVAR for malperfusion syndromes in acute DeBakey I aortic dissection. Ann Thorac Surg. 2017;103:748-55. 
19. Iafrancesco M, Goebel N, Mascaro J, Franke UFW, Pacini D, Di Bartolomeo R, et al. Aortic diameter remodelling after the frozen elephant trunk technique in aortic dissection: results from an international multicentre registry. Eur J Cardiothorac Surg. 2017;52:310-8.

20. Tsai TT, Evangelista A, Nienaber CA, Myrmel T, Meinhardt G, Cooper JV, et al. Partial thrombosis of the false lumen in patients with acute Type B aortic dissection. N Engl J Med. 2007;357:349-59.

Key Words: aortic dissection, aortic operation, imaging

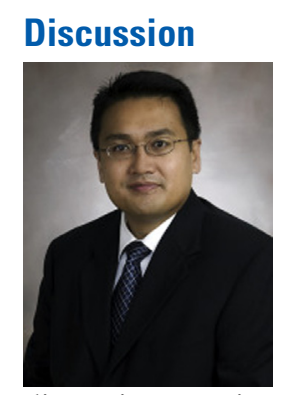

Dr Anthony L. Estrera (Houston, Tex). I have nothing to disclose regarding this presentation. Congratulations, Dr Heo, on a nicely presented article. The authors previously demonstrated the unfavorable remodeling that has occurred when residual dissection involves the arch vessels after type A dissection repair after open conventional repair, basically hemiarch repair. Moving more distally, in this article they wanted to analyze the effect of the tear on dissection on longer-term outcomes with regard to type A dissection repair and performed and excluded all the patients who did not have total arch replacement.

They examined 40 patients, 26 with total arch replacement and 14 with FET, and found that tears greater than $3 \mathrm{~mm}$ in length in the proximal descending thoracic aorta, or the zone 1 area, were associated with an increased rate of aortic growth, thus unfavorable remodeling. Although the cohort is small, the authors provide some corroborating data and similar to what we know currently that occurs with acute type $\mathrm{B}$ aortic dissection.

I have a few questions for you. Although you identified the factors for unfavorable remodeling, you observed no difference in the reintervention rates between total arch replacement and the FET procedure. What were the reinterventions that you performed in those 2 groups, and acknowledging the fact that this was a small cohort, why do you think the FET in that group did not reduce the number of reinterventions?

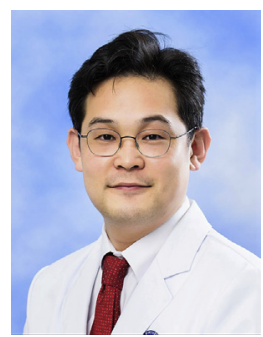

Dr Woon Heo (Seoul, Republic of Korea). In the FET group, 3 patients needed reintervention. One case was zone 3 TEVAR for a level I tear, 1 case was zone 3 TEVAR for distal anastomotic leak, and 1 case was zone 4 TEVAR for a level II tear. I believe in the preventive effect of FET, but it is limited to selected patients, not for all.

The best action to take when you find a proximal DTA tear in the surgical field is to resect and replace it. If you see the tear but can't replace it, then the FET for antegrade TEVAR in the future is good as a fallback.
But the philosophy, I believe, is more procedures, more complications. FET is clearly beneficial for the selected patient, but it does have its downside: spinal cord injury and unavailability of cerebrospinal fluid drain limit the distal length of the device. Also, I think the FET covering a short segment of proximal DTA does not have much effect on the reintervention rate in the distal portion because of the remnants dissected near the DTA and abdominal aorta. So I am curious about how the rate will turn out as we gather more data.

Dr Estrera. As we all know about aortic dissection, these pinholes may keep (and Eric had a nice presentation on this at the symposium) the FL pressurized. How did you decide on $3 \mathrm{~mm}$ as that tear size that was significant in your study? Could these pinholes, or you just couldn't see them, be the reason why you didn't have complete thrombosis at the level of the stent graft when you did do FET procedures?

Dr Heo. The only reason for $3 \mathrm{~mm}$ is that our aorta CT protocol is $3 \mathrm{~mm}$. I did not mention it in the presentation, but dramatic diameter changes were seen in 5-mm size as a cutoff, but in 5-mm size the Kaplan-Meier curve for reintervention was not statistically significant. I think it is probably due to the small number of cases. Of course, a pinhole can be the reason. You can see on this table, the no tear group in the table, no tear means no tear larger than $3 \mathrm{~mm}$, not no tear at all. The 3 patients in this no tear group showed complete thrombosis in level III. They also achieved complete thrombosis at levels I and II, but this is only $25 \%$. I know the extent may vary, but pinhole does have its effect on aortic remodeling.

In our cases, 1 patient who had a level I tear did not need reintervention, even with 6 tears larger than $5 \mathrm{~mm}$ in pulmonary artery bifurcation or abdominal aorta, all levels. The maximal diameter was only $30 \mathrm{~mm}$. As time passes, it will grow, but the higher tear count does not necessarily mean you need reintervention. I think for these reasons, hemodynamics of dissected aorta with intimal tear is important. So I am interested in the computational fluid dynamics study. I believe it will have the answer for this.

Dr Estrera. How have these data changed how you approach and how aggressive you are with the operation for acute type A dissection?

Dr Heo. About 3 or 4 years ago, we did have a phase when we frequently used the FET procedure. With patients excluded from this study, I believe about 3 patients with type I dissection underwent FET. The problem was that FET could not solve the aortic growth because of the retrograde flow from the different reentry.

So our indications for FET are penetrating atherosclerotic ulcer or aneurysmal change and intimal tear at the proximal DTA, but the most important one is that we do it only if the distal landing can be done safely. So with inadequate graft size or in case of acute aortic angulation, we did not perform FET, and the length of the device, which is around the 
seventh thoracic vertebra for spinal cord protection, in many cases this is not enough for this tear. Antegrade TEVAR is technically more difficult than retrograde TEVAR. So we adopted the elephant trunk technique instead; $5 \mathrm{~cm}$ of graft is left in the descending aorta. And when the thoracic aorta needs treatment, we do the retrograde zone 3 TEVAR. I think this has been effective.

Dr Estrera. Are you postulating that the descending tear at level I was the original causative tear for the type A dissection or did they all have a typical circumferential tear near the coronary arteries?

Dr Heo. You mean the retrograde type?

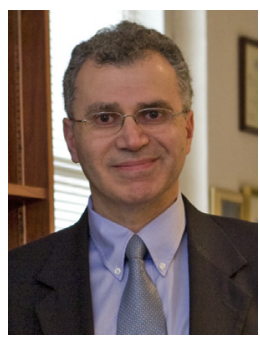

Dr John Elefteriades (New Haven, Conn). What do you think you are studying? Are you studying the original tear that caused a retrograde dissection?

Dr Heo. No. We excluded retrograde type A dissections. So they all had it in ascending or arch.

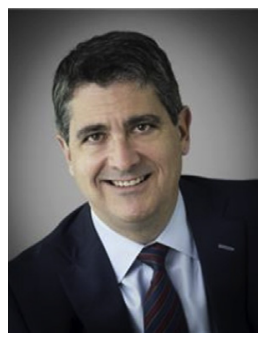

Dr Roselli. To that point, it's kind of impossible to tell, isn't it, if there is a tear in the ascending and the proximal descending, which one is the tear and which one is the reentry tear? Kind of hard to tell, isn't it?
Dr Elefteriades. Yes, but did you look at the operative notes or do you know that they all had a tear in the ascending aorta?

Dr Heo. Ascending or arch, yes.

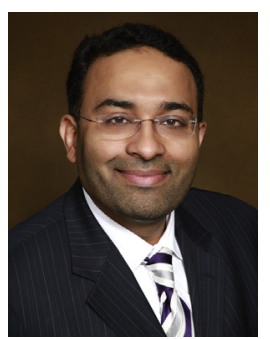

Dr Muhammad Aftab (Aurora, Colo). Excellent presentation. Looking at your presentation and reviewing your data, my take-home message, and please correct me if I am wrong, is that if you see a descending aortic tear, residual tear, total arch replacement is still an inadequate procedure on these patients. Then you would be better performing a FET in the same setting or during the same hospitalization and bring the patient back in 72 hours or some predetermined time and reintervene before discharge to give the best chance of aortic remodeling. Would you agree with this?

Dr Heo. Pardon?

Dr Roselli. I will answer the question because we are out of time. I totally agree with you, Mo. I think this study lends some credence to us being more aggressive about treating those tears beyond the ascending aorta but within the thoracic aorta. We probably have to get better at performing a FET technique that is modified to the indication of acute dissection, as you suggested. 
TABLE E1. Diameter and growth rate of each level of the aorta by the first location of intimal tear ( $\geq \mathbf{3} \mathrm{mm}$ )

\begin{tabular}{|c|c|c|c|c|c|}
\hline \multirow[b]{2}{*}{ Variable } & \multicolumn{4}{|c|}{ First location of intimal tear $(\geq \mathbf{3} \mathbf{~ m m})$} & \multirow[b]{2}{*}{$P$ value } \\
\hline & No tear $(n=12)$ & Level $1(n=5)$ & Level $2(n=5)$ & Level $3(n=18)$ & \\
\hline \multicolumn{6}{|l|}{ First CT scan } \\
\hline PAB level & $34.4[33.5-36.0]$ & $32.2[32.2-39.0]$ & $33.7[32.2-35.7]$ & $36.4[30.9-37.8]$ & .838 \\
\hline $\mathrm{TL}$ & $18.8[14.1-23.1]$ & $11.4[9.6-11.5]$ & $21.5[21.4-23.6]$ & $17.1[15.2-20.7]$ & .023 \\
\hline FL & $15.8[12.1-20.4]$ & $20.8[20.7-28.0]$ & $10.8[7.5-12.2]$ & $18.6[13.1-20.9]$ & .702 \\
\hline $\mathrm{CA}$ & $30.9[29.6-34.3]$ & $28.8[28.3-31.6]$ & $30.2[28.2-30.8]$ & $28.1[25.7-31.4]$ & .031 \\
\hline TL & $14.8[12.9-17.0]$ & $13.2[7.9-14.9]$ & $15.0[14.0-15.3]$ & 13.4 [11.6-14.7] & .448 \\
\hline FL & $15.9[13.3-19.0]$ & $18.3[15.1-19.5]$ & $15.5[15.2-19.1]$ & $15.0[13.1-16.8]$ & .189 \\
\hline MaxAA & $24.4[23.2-26.6]$ & $26.6[23.8-31.7]$ & $29.3[25.9-31.8]$ & $24.8[23.2-26.3]$ & .580 \\
\hline $\mathrm{TL}$ & $13.0[12.0-15.0]$ & $11.1[8.4-14.4]$ & $14.8[13.5-15.2]$ & $11.8[10.5-13.9]$ & .876 \\
\hline FL & $11.5[8.7-15.8]$ & $12.7[12.2-17.2]$ & $13.8[12.1-16.6]$ & $12.6[11.0-13.9]$ & .713 \\
\hline MaxTAA & $35.5[34.4-36.0]$ & $36.0[35.7-42.3]$ & $33.7[32.2-36.7]$ & $37.0[30.9-39.5]$ & .587 \\
\hline \multicolumn{6}{|l|}{ Last CT scan } \\
\hline $\mathrm{PAB}$ & 36.4 [30.9-41.2] & $49.3[48.3-50.9]$ & $31.3[30.6-35.2]$ & $31.4[29.3-41.7]$ & .136 \\
\hline $\mathrm{TL}$ & $24.8[20.8-28.4]$ & $11.6[11.2-17.6]$ & $28.4[25.4-30.0]$ & $26.2[19.4-28.4]$ & .020 \\
\hline FL & $8.4[3.6-18.8]$ & $32.6[31.7-37.1]$ & $2.2[2.0-2.2]$ & $4.2[2.3-17.1]$ & .004 \\
\hline $\mathrm{CA}$ & $29.9[26.4-38.2]$ & $38.3[34.9-38.5]$ & $28.2[27.3-34.9]$ & $32.5[31.1-33.3]$ & .882 \\
\hline TL & $17.5[10.5-20.6]$ & $11.8[6.9-15.6]$ & $22.3[15.2-25.3]$ & $14.2[10.2-16.5]$ & .839 \\
\hline FL & $18.1[7.3-24.7]$ & $22.6[22.4-26.7]$ & $12.1[3.8-12.4]$ & $17.7[15.0-22.1]$ & .975 \\
\hline MaxAA & $26.8[23.3-31.0]$ & $31.6[31.5-33.9]$ & $27.1[26.0-34.9]$ & $29.1[27.7-30.4]$ & .427 \\
\hline $\mathrm{TL}$ & $12.1[10.1-17.7]$ & $10.1[6.7-15.1]$ & $16.3[13.4-18.1]$ & $13.3[10.1-15.0]$ & .911 \\
\hline FL & 14.4 [8.3-19.1] & $18.7[18.2-21.4]$ & $14.3[12.6-18.5]$ & $15.4[13.9-18.4]$ & .607 \\
\hline MaxTAA & $38.7[30.9-42.0]$ & $49.3[48.3-50.9]$ & $37.1[31.3-44.3]$ & $33.6[31.9-41.7]$ & .345 \\
\hline \multicolumn{6}{|l|}{ Growth rate } \\
\hline PAB & $5.5[-9.1-16.7]$ & $40.1[23.8-53.1]$ & $-1.6[-2.8--1.4]$ & $-8.2[-16.2-15.8]$ & .020 \\
\hline TL & $23.6[6.2-96.0]$ & $16.7[16.3-54.4]$ & $20.3[18.1-37.9]$ & $41.8[26.8-50.3]$ & .604 \\
\hline FL & $-31.4[-78.0-18.9]$ & $52.4[26.2-57.5]$ & $-70.7[-83.6$ to -37.1$]$ & $-76.3[-86.9$ to -12.9$]$ & .020 \\
\hline $\mathrm{CA}$ & $-0.5[-7.4-14.4]$ & $25.3[23.3-33.7]$ & $0.0[-2.6-13.9]$ & $15.4[8.3-26.0]$ & .070 \\
\hline TL & $0.6[-28.5-25.4]$ & $-11.7[-15.2-18.2]$ & $9.6[-0.7-80.7]$ & $9.6[-4.7-23.3]$ & .567 \\
\hline FL & $15.4[-48.0-37.8]$ & $27.8[23.5-38.8]$ & $-35.1[-54.8$ to -21.9$]$ & $28.0[0.8-41.7]$ & .349 \\
\hline MaxAA & $5.6[-0.6-18.0]$ & $14.8[14.1-18.8]$ & $20.4[2.5-22.5]$ & $20.7[14.4-23.8]$ & .015 \\
\hline TL & $-0.4[-13.8-28.1]$ & $-3.8[-9.0-4.9]$ & 34.7 [1.2-34.9] & $13.5[-8.1-24.0]$ & .382 \\
\hline FL & $22.6[-21.7-47.9]$ & $35.2[12.9-58.3]$ & $3.8[3.7-10.2]$ & $27.5[7.9-47.7]$ & .624 \\
\hline MaxTAA & $6.9[-4.6-17.4]$ & $38.1[15.3-40.1]$ & $0.5[-1.6-20.7]$ & $4.7[-10.1-13.2]$ & 624 \\
\hline
\end{tabular}

$C T$, Computed tomography; $P A B$, pulmonary artery bifurcation; $T L$, true lumen; $F L$, false lumen; $C A$, celiac axis; MaxAA, maximal diameter of abdominal aorta; MaxTAA, maximal diameter of thoracoabdominal aorta.

TABLE E2. False lumen status (thrombosis) according to the first location of intimal tear ( $>3 \mathbf{m m})$

\begin{tabular}{|c|c|c|c|c|c|}
\hline \multirow[b]{2}{*}{ Variable } & \multicolumn{4}{|c|}{ First location of intimal tear $(\geq 3 \mathrm{~mm})$} & \multirow[b]{2}{*}{$P$ value } \\
\hline & No tear $(n=12)$ & Level $1(n=5)$ & Level $2(n=5)$ & Level $3(n=18)$ & \\
\hline Level 1 & & & & & .031 \\
\hline Complete & $8(66.7 \%)$ & $0(0.0 \%)$ & $4(80.0 \%)$ & $12(66.7 \%)$ & \\
\hline Partial or patent & $4(33.3 \%)$ & $5(100.0 \%)$ & $1(20.0 \%)$ & $6(33.3 \%)$ & \\
\hline Level 2 & & & & & .092 \\
\hline Complete & $5(41.7 \%)$ & $0(0.0 \%)$ & $0(0.0 \%)$ & $8(44.4 \%)$ & \\
\hline Partial or patent & $7(58.3 \%)$ & $5(100.0 \%)$ & $5(100.0 \%)$ & $10(55.6 \%)$ & \\
\hline Level 3 & & & & & .070 \\
\hline Complete & $3(25.0 \%)$ & $0(0.0 \%)$ & $0(0.0 \%)$ & $0(0.0 \%)$ & \\
\hline Partial or patent & $9(75.0 \%)$ & $5(100.0 \%)$ & $3(100.0 \%)$ & $18(100.0 \%)$ & \\
\hline
\end{tabular}


TABLE E3. Diameter and growth rate of each level of the aorta of the non-frozen elephant trunk and frozen elephant trunk groups

\begin{tabular}{|c|c|c|c|}
\hline Variables & Non-FET $(n=26)$ & FET $(n=14)$ & $P$ value \\
\hline \multicolumn{4}{|l|}{ First CT scan } \\
\hline PAB level & $35.8[33.4-37.8]$ & 34.0 [31.1-36.9] & .435 \\
\hline $\mathrm{TL}$ & $15.2[11.4-18.8]$ & 22.4 [18.8-24.7] & .001 \\
\hline FL & 20.4 [15.7-21.2] & $10.9[7.5-15.4]$ & $<.001$ \\
\hline CA & $28.6[27.3-32.7]$ & $30.1[28.3-31.6]$ & .512 \\
\hline $\mathrm{TL}$ & $14.0[11.8-16.1]$ & $14.2[10.3-15.3]$ & .728 \\
\hline FL & $15.2[13.1-17.7]$ & $16.0[13.6-19.7]$ & .265 \\
\hline MaxAA & $25.1[23.2-26.6]$ & $24.4[23.4-27.2]$ & .691 \\
\hline $\mathrm{TL}$ & $12.3[10.7-15.3]$ & $12.6[10.5-13.3]$ & .336 \\
\hline FL & $12.6[11.5-13.3]$ & 12.9 [10.7-18.7] & .231 \\
\hline MaxTAA & $36.0[34.9-38.3]$ & 34.0 [31.1-36.9] & .152 \\
\hline \multicolumn{4}{|l|}{ Last CT scan } \\
\hline PAB & $33.0[29.3-44.5]$ & $32.5[30.6-40.5]$ & .820 \\
\hline $\mathrm{TL}$ & $24.1[15.1-26.6]$ & $27.6[22.3-29.6]$ & .089 \\
\hline FL & $6.8[2.7-27.8]$ & 4.1 [2.2-14.9] & .197 \\
\hline $\mathrm{CA}$ & $32.0[28.3-36.4]$ & $32.3[27.3-37.5]$ & .954 \\
\hline $\mathrm{TL}$ & 14.4 [10.2-18.3] & $15.3[10.8-20.6]$ & .838 \\
\hline FL & $19.6[14.0-23.1]$ & $16.0[12.1-22.1]$ & .921 \\
\hline MaxAA & $29.4[25.3-31.6]$ & $28.6[27.1-31.1]$ & 1.00 \\
\hline TL & $13.7[10.1-15.2]$ & $12.0[10.3-16.3]$ & .925 \\
\hline FL & 15.3 [13.6-18.7] & 16.4 [13.9-18.4] & .897 \\
\hline MaxTAA & 38.0 [32.8-46.7] & 33.5 [31.3-41.7] & .257 \\
\hline \multicolumn{4}{|l|}{ Growth rate } \\
\hline PAB & $1.1[-15.4-23.8]$ & $-0.0[-2.8-6.6]$ & .932 \\
\hline TL & $43.6[25.9-59.1]$ & 13.9 [2.4-37.9] & .003 \\
\hline FL & $-60.9[-83.4-26.2]$ & $-36.8[-74.8-22.8]$ & .910 \\
\hline $\mathrm{CA}$ & $12.4[0.0-27.7]$ & $13.4[-0.4-15.9]$ & .482 \\
\hline $\mathrm{TL}$ & $7.9[-11.7-21.5]$ & $2.4[-15.2-32.1]$ & .977 \\
\hline FL & $25.7[0.8-38.9]$ & $13.7[-21.9-38.8]$ & .543 \\
\hline MaxAA & $14.6[8.1-23.0]$ & 19.4 [14.8-21.5] & .608 \\
\hline $\mathrm{TL}$ & $0.7[-13.0-19.5]$ & $21.0[-12.2-35.1]$ & .214 \\
\hline FL & $27.8[7.4-53.0]$ & $16.6[3.8-46.8]$ & .594 \\
\hline MaxTAA & $13.1[-10.1-22.0]$ & $3.4[-1.6-11.5]$ & .463 \\
\hline
\end{tabular}

$F E T$, Frozen elephant trunk; $C T$, computed tomography; $P A B$, pulmonary artery bifurcation; $T L$, true lumen; $F L$, false lumen; $C A$, celiac axis; $M a x A A$, maximal diameter of abdominal aorta; MaxTAA, maximal diameter of thoracoabdominal aorta.

TABLE E4. False lumen status (thrombosis) of the non-frozen elephant trunk and frozen elephant trunk groups

\begin{tabular}{lccc}
\hline \multicolumn{1}{c}{ Variables } & Non-FET $(\mathbf{n}=\mathbf{2 6})$ & FET $(\mathbf{n}=\mathbf{1 4})$ & $\boldsymbol{P}$ value \\
\hline Level 1 & & & .946 \\
$\quad$ Complete & $15(57.7 \%)$ & $9(64.3 \%)$ & \\
$\quad$ Partial or patent & $11(42.3 \%)$ & $5(35.7 \%)$ & \\
Level 2 & & & .972 \\
$\quad$ Complete & $9(34.6 \%)$ & $4(28.6 \%)$ & \\
$\quad$ Partial or patent & $17(65.4 \%)$ & $10(71.4 \%)$ & \\
Level 3 & & & 1.00 \\
$\quad$ Complete & $2(8.0 \%)$ & $1(7.7 \%)$ & \\
$\quad$ Partial or patent & $23(92.0 \%)$ & $12(92.3 \%)$ & \\
\hline
\end{tabular}

FET, Frozen elephant trunk.
TABLE E5. Reintervention rate according to first location of the intimal tear $(\geq 3 \mathbf{~ m m})$

\begin{tabular}{cccccc}
\hline & \multicolumn{5}{c}{ First location of intimal tear $(\geq \mathbf{3} \mathbf{~ m m})$} \\
\cline { 2 - 7 } Variable & $\begin{array}{c}\text { No tear } \\
(\mathbf{n}=\mathbf{1 2})\end{array}$ & $\begin{array}{c}\text { Level 1 } \\
(\mathbf{n}=\mathbf{5})\end{array}$ & $\begin{array}{c}\text { Level 2 } \\
(\mathbf{n}=\mathbf{5})\end{array}$ & $\begin{array}{c}\text { Level 3 } \\
(\mathbf{n}=\mathbf{1 8})\end{array}$ & $\boldsymbol{P}$ value \\
\hline Intervention & $1(8.3 \%)$ & $4(80.0 \%)$ & $2(40.0 \%)$ & $3(16.7 \%)$ & .011 \\
\hline
\end{tabular}

TABLE E6. Reintervention rate according to the use of frozen elephant trunk

\begin{tabular}{lllc}
\hline Variable & Non-FET $(\mathbf{n}=\mathbf{2 6})$ & FET $(\mathbf{n}=\mathbf{1 4})$ & $\boldsymbol{P}$ value \\
\hline Intervention & $7(26.9 \%)$ & $3(21.4 \%)$ & 1.00 \\
\hline FET, Frozen elephant trunk.
\end{tabular}

